American Journal of Pharmaceutical Education 2017; 81 (7) Article 5928.

\title{
RESEARCH
}

\section{Educational Attainment and Academic Profile of Deans and Chairs at US Pharmacy Schools}

\author{
Mitra Assemi, PharmD, ${ }^{\text {a }}$ Jessica Yu, PharmD, ${ }^{\text {a }}$ Sum Liu, PharmD, ${ }^{\text {a }}$ Robin L. Corelli, PharmD, \\ Karen Suchanek Hudmon, DrPH, MS ${ }^{\mathrm{a}, \mathrm{b}}$ \\ ${ }^{a}$ University of California, San Francisco School of Pharmacy, San Francisco, California \\ ${ }^{\mathrm{b}}$ Purdue University College of Pharmacy, Indianapolis, Indiana \\ Submitted July 13, 2016; accepted November 16, 2016; published September 2017.
}

Objective. To characterize educational attainment and experiences of current US pharmacy school deans and chairs.

Methods. A cross-sectional study using a publicly available listing of accredited schools and information. Results. Among 134 deans and 301 chairs, $79.9 \%$ and $65.5 \%$ held a professional degree (BSPharm and/or PharmD), 33.6\% and 26.2\% completed PGY-1 residencies, $12.7 \%$ and $15.6 \%$ completed post-PharmD fellowships, $23.1 \%$ and $33.9 \%$ completed post-doctoral fellowships, and $13.4 \%$ and $18.3 \%$ held BPS certification, respectively. Fewer than 1 in 5 were employed at an alma mater. Ninety $(20.7 \%)$ deans and chairs completed AACP's Academic Leadership Fellows Program. Average current tenure was 5.7 and 5.1 years for deans and chairs, respectively.

Conclusion. The majority of deans and chairs held a pharmacy professional degree and the prevalence of post-graduate educational and leadership training is increasing. Future research should apply mixed methods to investigate educational attainment and employment experience of deans and chairs, institutional hiring trends, and how these characteristics compare between newer and established programs.

Keywords: pharmacy education, pharmacy dean, pharmacy chair, leadership, workforce

\section{INTRODUCTION}

The number of pharmacy schools in the United States has increased rapidly over the past two decades. Between 2004 and 2014, the number with full accreditation or candidate status increased by $50 \%$, from 86 to $129 .^{1,2}$ This proliferation in new programs poses potential challenges, including the recruitment and retention of qualified faculty and leadership teams. ${ }^{3}$

Recently, Assemi and colleagues ${ }^{2}$ characterized the educational background and degrees of faculty members at US pharmacy schools. In 2011, more than two-thirds (68.5\%) of faculty members held a pharmacy professional degree (BSPharm and/or PharmD), and an estimated 1 in 5 held faculty positions at the institution where they had obtained their professional degree. Furthermore, newer schools (defined as those established after 1995) , $^{4,5}$ had fewer faculty and a lower mean faculty rank compared to more established schools.

Corresponding Author: Mitra Assemi, University of California, San Francisco School of Pharmacy, 533 Parnassus Ave. [U-585], Box 0622, San Francisco, CA 94143-0622.

Tel: 559-499-6515. Fax: 559-499-6513.

E-mail: Mitra.Assemi@ucsf.edu
In the most recent Standards 2016, the Accreditation Council for Pharmacy Education (ACPE) outlines the expectations for the deans and leadership teams of US pharmacy schools. ${ }^{6}$ Standard 8.2 describes a qualified dean as one who "is qualified to provide leadership in pharmacy professional education and practice, research and scholarship, and professional and community service." Standard 8.3 describes a qualified administrative team with the expectations that "the dean and other college or school administrative leaders have credentials and experience that have prepared them for their respective roles and collectively have the needed backgrounds to effectively manage the educational program." While these standards provide some guidance regarding acceptable qualifications for pharmacy academic leaders, the described requirements are vague and subjective.

Previous studies have investigated various aspects of pharmacy academic leadership qualifications with respect to demographic information, academic degrees held, previous academic rank, migratory paths (career paths and progressions), and publication records of deans and departmental chairs. ${ }^{7-10}$ A descriptive study by Schwinghammer and colleagues surveyed US pharmacy department chairs in 2010 and reported academic degrees 


\section{American Journal of Pharmaceutical Education 2017; 81 (7) Article 5928.}

held (PharmD, PhD, master's, other doctoral), previous professoriate appointments, job satisfaction, and motivations for chairmanship. ${ }^{7}$ In 2009, US pharmacy deans were surveyed to characterize age, race, sex, highest terminal degree earned, years in professoriate prior to deanship, length of tenure, and career path, and these results built upon what was gleaned from three earlier studies. ${ }^{8}$ Since publication of these reports, pharmacy education has continued to experience unparalleled growth in the number of programs coupled with ongoing, rapid changes in higher education and health care. As such, the current composition of pharmacy academic leadership within this environment is unknown.

The objective of this study was to characterize US pharmacy deans and chairs with respect to their educational background and training, year of appointment for their current dean or chair position, employment at an alma mater school, and whether they held a previous appointment as dean at another institution. This study builds upon prior research by characterizing educational attainment among current US pharmacy school deans and chairs including degrees obtained, post-graduate training and board certifications, and graduation from the American Association of Colleges of Pharmacy (AACP) Academic Leadership Fellows Program (ALFP). Collectively, these factors provide additional insight into the educational pathways traveled for individuals who have risen into these leadership roles. Given the continued rapid growth in the number of pharmacy schools and current shortage of faculty, including leaders, our results provide a contemporary baseline for informing future research into the recruitment and development of academic leadership.

\section{METHODS}

In July 2015, an updated list of accredited pharmacy schools $(n=135)$, defined as those with pre-candidate, candidate, and full accreditation status, was obtained from the ACPE website. ACPE-accredited schools located outside the US (Puerto Rico and Lebanon) were excluded, yielding a total of 133 schools. All deans and chairs identified at these 133 schools between July and October 2015 were included in the study.

Detailed internet searches were performed to obtain the following information for each dean and chair: appointment year as the permanent or interim dean or chair position, degrees obtained (BSPharm, PharmD, master's, $\mathrm{PhD}$, or other doctoral degrees), year of conferral and awarding institution, post-graduate training in residencies (PGY-1 or PGY-2) or fellowships (post-PharmD or post$\mathrm{PhD}$ ), other credentials (eg, board of pharmacy specialties, other), current employment at alma mater school (for
BSPharm, PharmD, and/or PhD degree), hereafter described as "promotion from within," and previous appointment as dean at another institution. The initial source for this information was the school website, including leadership, departmental, and individual faculty web pages. If information was not available from these sources, the investigators conducted searches on Linked In and Google. Unobtainable data fields were coded as missing data. Data characterizing graduation from the fellowship program (ALFP) was obtained from the AACP website. ${ }^{11}$ For quality assurance purposes, the two data collectors cross-verified each other's databases. A separate quality assurance check of approximately $13 \%$ of all records was conducted by three investigators.

Standard descriptive statistics and Chi-squared analyses were conducted to compare proportions using SPSS, version 23 (IBM, Armonk, NY). For deans holding two or more degrees, with one being a $\mathrm{PhD}$, the $\mathrm{PhD}$ was considered the highest terminal degree. To determine the contributions of individual schools of pharmacy toward academic leadership, the conferring institution for each degree held by a dean or chair was included in a combined frequency analysis, with each degree being equally weighted. If an individual received more than one degree from the same institution, that institution received credit (ie, was counted) for each degree. The extent of promotion from within for leadership was estimated for each school of pharmacy by summing the number of deans and chairs who had received one or more degrees from the same institution where they held their current deanship or chair appointment. For the promotion from within among leadership analyses, the Charleston and Columbia campuses of the University of South Carolina were combined.

\section{RESULTS}

Of the 133 ACPE-accredited schools included in the study, 134 deans and 301 chairs were identified and included for data collection and analysis. One university had two campuses, each with its own dean. The curricula vitae for $23(17.2 \%)$ deans and $68(22.6 \%)$ chairs were available through the official university websites.

A total of 107 deans (79.9\%) and 197 chairs (65.5\%) held a pharmacy professional degree (BSPharm and/or PharmD). Tables 1 and 2 display the educational background of deans and chairs. Overall, an estimated 24.6\% and $37.5 \%$ held one degree, $50.7 \%$ and $45.2 \%$ held two degrees, and $24.6 \%$ and $15.9 \%$ held three degrees, respectively. Four chairs (1.3\%) held four degrees. Table 3 summarizes trends over the last 25 years in highest degree earned for deans. 
American Journal of Pharmaceutical Education 2017; 81 (7) Article 5928.

Table 1. Education Attainment of Deans at US Pharmacy Schools, as of Fall $2015(n=134)^{\mathrm{a}}$

\begin{tabular}{|c|c|c|c|c|}
\hline Degree(s) Obtained & Additional Degree $^{b}$ & $\begin{array}{c}\text { Deans at Established } \\
\text { Schools } \\
n=78\end{array}$ & $\begin{array}{c}\text { Deans at Newer } \\
\text { Schools }^{\mathrm{d}} \\
\mathrm{n}=56\end{array}$ & $\begin{array}{c}\text { Deans at All Schools } \\
n=134\end{array}$ \\
\hline BSPharm only & - & 0 & $1(1.8)$ & $1(0.7)$ \\
\hline PharmD only & - & $9(11.5)$ & $9(16.1)$ & $18(13.4)$ \\
\hline $\mathrm{PhD}$ only & - & $11(14.1)$ & $3(5.4)$ & $14(10.5)$ \\
\hline $\begin{array}{l}\text { BSPharm and/or } \\
\text { PharmD only }\end{array}$ & - & $32(41.0)$ & $26(46.4)$ & $58(43.3)$ \\
\hline \multirow{3}{*}{$\begin{array}{l}\text { BSPharm with } \\
\text { additional degree }\end{array}$} & $\mathrm{PhD}$ & $22(28.2)$ & $12(21.4)$ & $34(25.4)$ \\
\hline & Master's & $20(25.6)$ & $11(19.6)$ & $31(23.1)$ \\
\hline & Other doctorate & $2(2.6)$ & $2(3.6)$ & $4(3.0)$ \\
\hline \multirow{3}{*}{$\begin{array}{l}\text { PharmD with } \\
\text { additional degree }\end{array}$} & $\mathrm{PhD}$ & $3(3.8)$ & $2(3.6)$ & $5(3.7)$ \\
\hline & Master's & $4(5.1)$ & $4(7.1)$ & $8(6.0)$ \\
\hline & Other doctorate & 0 & 0 & 0 \\
\hline \multirow{2}{*}{$\begin{array}{l}\text { PhD with additional } \\
\text { degree }\end{array}$} & Master's & $20(25.6)$ & $14(25.0)$ & $34(25.4)$ \\
\hline & Other doctorate & 0 & $1(1.8)$ & $1(0.7)$ \\
\hline
\end{tabular}

${ }^{a}$ Presented as n (\%)

b، Additional degree" does not imply that only one additional degree is held

${ }^{\mathrm{c}}$ Program established before 1996

${ }^{\mathrm{d}}$ Program established 1996-present

Post-graduate training obtained by deans and chairs is depicted in Figure 1. Eighteen deans (13.4\%) and 55 chairs $(18.3 \%)$ held a BPS certification. Among both groups, the most common board certification was board certified pharmacotherapy specialist (BCPS; 8 deans, 39 chairs), followed by board certified psychiatric pharmacist (BCPP; 2 deans, 6 chairs). With respect specifically to formal academic leadership development, 90 of 435 (20.7\%) deans and chairs have graduated from AACP's fellowship program (ALFP) since its inception in 2004.
Of these, 27 (20.2\%) were deans and 63 (20.9\%) were chairs.

Fewer than 1 in 5 deans and chairs $(11.9 \%$ and $18.9 \%$, respectively) were currently employed at an alma mater school of pharmacy where they had obtained their BSPharm, PharmD, and/or PhD degree. Most schools (87 of $133 ; 65.4 \%$ ) had no prior graduates from their own institution, or promotion from within, among their deans and chairs. A total of 24 schools $(17.9 \%)$ had promotion from within for one dean or chair, $18(13.5 \%)$ schools had

Table 2. Education Attainment of Chairs at US Pharmacy Schools, as of Fall $2015(\mathrm{n}=301)^{\mathrm{a}}$

\begin{tabular}{|c|c|c|c|c|}
\hline Degree(s) Obtained & $\begin{array}{l}\text { Additional } \\
\text { Degree }^{b}\end{array}$ & $\begin{array}{c}\text { Chairs at Established Schools } \\
(\mathrm{n}=199)\end{array}$ & $\begin{array}{c}\text { Chairs at Newer Schools }^{\mathrm{d}} \\
(\mathrm{n}=102)\end{array}$ & $\begin{array}{c}\text { Chairs at All Schools } \\
(\mathrm{n}=301)\end{array}$ \\
\hline BSPharm only & - & 0 & $1(1.0)$ & $1(0.3)$ \\
\hline PharmD only & - & $22(11.1)$ & $21(20.6)$ & $43(14.3)$ \\
\hline PhD only & - & $56(28.1)$ & $13(12.7)$ & $69(22.9)$ \\
\hline $\begin{array}{l}\text { BSPharm and/or } \\
\text { PharmD only }\end{array}$ & - & $61(30.7)$ & $43(42.2)$ & $104(34.6)$ \\
\hline \multirow{3}{*}{$\begin{array}{l}\text { BSPharm with } \\
\text { additional degree }\end{array}$} & $\mathrm{PhD}$ & $40(20.1)$ & $23(22.5)$ & $63(20.9)$ \\
\hline & Master's & $30(15.1)$ & $12(11.8)$ & $42(14.0)$ \\
\hline & Other doctorate & $1(0.5)$ & $1(1.0)$ & $2(0.7)$ \\
\hline \multirow{3}{*}{$\begin{array}{l}\text { PharmD with } \\
\text { additional degree }\end{array}$} & $\mathrm{PhD}$ & $9(4.5)$ & $6(5.9)$ & $15(5.0)$ \\
\hline & Master's & $13(6.5)$ & $9(8.8)$ & $22(7.3)$ \\
\hline & Other doctorate & $2(1.0)$ & $2(2.0)$ & $4(1.3)$ \\
\hline \multirow{2}{*}{$\begin{array}{l}\mathrm{PhD} \text { with additional } \\
\text { degree }\end{array}$} & Master's & $48(24.1)$ & $21(20.6)$ & $69(22.9)$ \\
\hline & Other doctorate & $4(2.0)$ & $2(2.0)$ & $6(2.0)$ \\
\hline
\end{tabular}

${ }^{\mathrm{a}}$ Presented as $\mathrm{n}(\%)$

b، Additional degree" does not imply that only one additional degree is held

${ }^{c}$ Program established before 1996 ( $n=78$ schools)

${ }^{\mathrm{d}}$ Program established 1996-present ( $\mathrm{n}=56$ schools) 
American Journal of Pharmaceutical Education 2017; 81 (7) Article 5928.

Table 3. Longitudinal Comparison of Highest Degree Earned for Deans at US Pharmacy Schools ${ }^{\mathrm{a}}$

\begin{tabular}{lccccc}
\hline $\begin{array}{l}\text { Highest Degree } \\
\text { Obtained }^{\mathbf{b}}\end{array}$ & $\begin{array}{c}\mathbf{1 9 9 1}^{\mathbf{c}} \\
\mathbf{( n = 6 7 )}\end{array}$ & $\begin{array}{c}\mathbf{1 9 9 6}^{\mathbf{c}} \\
\mathbf{( n = 7 6 )}\end{array}$ & $\begin{array}{c}\mathbf{2 0 0 2}^{\mathbf{c}} \\
\mathbf{( n = 8 3 )}^{\mathbf{n}=\mathbf{8})}\end{array}$ & $\begin{array}{c}\mathbf{2 0 0 9}^{\mathbf{c}} \\
(\mathbf{n}=\mathbf{1 1 0})\end{array}$ & $\begin{array}{r}\mathbf{2 0 1 5} \\
(\mathbf{n}=\mathbf{1 3 4})\end{array}$ \\
\hline Baccalaureate & 0 & 0 & 0 & $2(1.8)$ & $1(.7)$ \\
Master's & 0 & 0 & 0 & $2(1.8)$ & 0 \\
PharmD & $5(7.5)$ & $8(10.5)$ & $21(25.3)$ & $42(38.2)$ & $64(47.8)$ \\
PhD & $61(91.0)$ & $67(88.2)$ & $60(72.3)$ & $62(56.4)$ & $63(47.0)$ \\
Other & $1(1.5)$ & $1(1.3)$ & $2(2.4)$ & $2(1.8)$ & $6(4.5)^{\mathrm{d}}$ \\
\hline
\end{tabular}

${ }^{\mathrm{a}}$ Presented as $\mathrm{n}(\%)$

${ }^{\mathrm{b}}$ For individuals with both a PharmD and $\mathrm{PhD}$, the highest degree obtained was considered the $\mathrm{PhD}$

${ }^{\mathrm{c}}$ From Draugalis et al study, data summarized within Table 3 of reference \#8

${ }^{\mathrm{d}}$ Includes non-PhD or PharmD doctorates (ie, EdD, JD, MD)

promotion from within for two academic leadership positions and four $(3.1 \%)$ schools had promotion from within for more than three leadership positions.

Among deans with ascertainable appointment date data $(n=129$ of $134 ; 96.3 \%)$, the average number of years in their current position was 5.7 years (SD 5.7, range 0-28, including 13 coded zero because they had been appointed in 2015). Similarly, the average tenure for chairs at their current position $(\mathrm{n}=236$ of $301 ; 78.4 \%)$ was 5.1 years (SD 5.4, range 0-28; including 34 coded zero because they had been appointed in 2015). The majority of deans $(59.7 \%)$ and chairs $(63.6 \%)$ had five or fewer years in their current position. Fourteen deans (10.4\%) had been a dean at a prior institution, and four deans (3.0\%) had been a dean at two prior institutions.

Of all degrees earned (BSPharm, PharmD, and/or $\mathrm{PhD}$ ) by deans or chairs (Tables 1 and 2), the schools of pharmacy exhibiting the greatest contributions (ie, of the total number of degrees conferred) toward pharmacy leadership were as follows: University of Kentucky $(\mathrm{n}=23)$, University at Buffalo $(\mathrm{n}=19)$, University of Minnesota $(n=18)$, University of Tennessee $(n=18)$, The
Ohio State University $(\mathrm{n}=17)$, Mercer University $(n=16)$, The University of Texas $(n=16)$, University of California, San Francisco $(n=16)$, Purdue University $(n=15)$, and University of Georgia $(n=15)$.

Twenty-four degrees were earned by deans or chairs from institutions based in India, 14 were earned from institutions based in Canada, and 38 were earned from institutions in other countries outside the US. For three deans $(2.2 \%)$ and 31 chairs $(10.3 \%)$, the highest earned degree was conferred from an institution outside the US. New schools did not differ from established schools based on the proportion of deans and chairs possessing a degree from pharmacy schools outside the US $\left(\chi^{2}=.77 ; p=.38\right)$.

\section{DISCUSSION}

This study characterizes the educational background and training of deans and chairs at US pharmacy schools. Although ACPE does not define the specific requirements of qualified deans or chairs, the education and training profile of these individuals could potentially provide insight and trends for current pharmacy leaders and can provide a basis for comparison in the future.

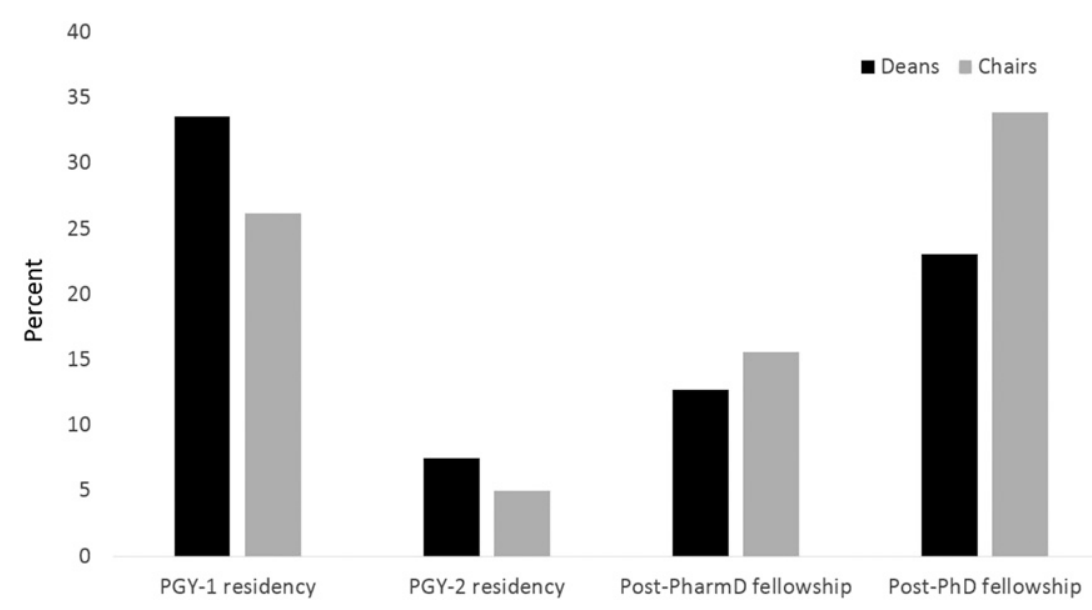

Figure 1. Post-graduate training of deans $(n=134)$ and chairs $(n=301)$ in US pharmacy schools, as of Fall 2015 


\section{American Journal of Pharmaceutical Education 2017; 81 (7) Article 5928.}

Our results indicate that more than half of deans and chairs hold a pharmacy professional degree. As shown in Table 3, the proportion of deans holding a PharmD versus a $\mathrm{PhD}$ as the highest degree earned has risen steadily over the last 25 years. Previous reports predicting this trend cited continued growth in the number of schools in relation to the pool of eligible candidates as a potential factor. ${ }^{8}$ One-third of deans and one-quarter of chairs also completed PGY-1 residencies, and some held Board of Pharmacy Specialties certifications. These findings are also consistent with continued growth in the proportion of deans holding professional degree and may correlate to pre-deanship career focus including patient- or population-based practice. While some have argued that pharmacy degree programs should be led by individuals within the profession, ${ }^{12}$ current accreditation standards for the PharmD degree do not mandate this. Others have expressed that effective deanship aligns not with terminal educational degree but an understanding of the evolving professional and health care landscape with a focus on patient centeredness. ${ }^{13}$ Given the dynamic changes that are occurring in the pharmacy profession, a professional background might provide an enhanced understanding of pharmacy practice, health care systems, and patientcentered care.

With respect to the proportion of chairs holding a professional degree, our results were consistent with those reported in 2012 by Schwinghammer and colleagues. ${ }^{7}$ The results for chairs may correlate to the split demographic among chairs between those leading pharmacy practice and administration versus science-related departments. Attainment of a pharmacy professional degree might not necessarily be a desired requirement for a basic science department chair, but it can be a reasonable expectation for a pharmacy practice department chair who might oversee clinical programs and curricula related to patient- and population-based care. Enhanced understanding of health care system and delivery and patient care by both deans and chairs, in turn, could help ensure professional degree programs and their faculty and students are focused on and accountable to both the profession and the public. Our findings also show variation in educational attainment with approximately half of deans and chairs possessing at least two degrees (BSPharm, PharmD, PhD, master's, and/or other doctorates). Diversely trained deans and chairs might be better equipped to lead within academic organizations with missions that focus equally on research, education, patient care, and public service.

Since 2004, approximately $20 \%$ of current deans and chairs have completed AACP's ALFP. The proportion of deans participating in this program was higher than that reported in $2010^{8}(7.6 \% ; n=4)$ and might reflect both a growing awareness and recognition of the value of this resource for current, new, and aspiring deans. The percentage of chairs participating in the ALFP was slightly lower $(20.9 \% ; n=63$ of 301$)$ than that reported by Schwinghammer and colleagues in 2012 (28\%; no absolute numbers provided). ${ }^{7}$ This lack of comparative data impeded determination of the potential significance of this result for chairs. Experiential diversity in the form of both educational and professional training among deans and chairs can have important implications for pharmacy academia because many of these leaders take both academic and administrative roles. Diverse disciplines and professional experiences among leadership ranks can provide intellectually stimulating environments and innovative perspectives to guide faculty and students in achieving the mission and vision of the school or department. $^{14}$

The majority of US pharmacy schools had no alumni, or academic promotion from within, among leadership. About $11.9 \%$ of deans and $18.9 \%$ of chairs, however, were currently employed by the school where they received their BSPharm, PharmD, and/or PhD degree(s). This analysis did not, however, consider host institutions for residency or fellowship trainings. These results are slightly lower than those observed overall for faculty in $2013 .^{2}$ Differences in the time frame for graduating and becoming a faculty member versus rising into a chair or dean position might account for the difference. It is unknown whether the driving force for the observed trends in employment stemmed from personal career goals to serve as leaders at their alma mater, institutional preferences to promote from within, or inability or unwillingness to move to a different geographic location. Some studies have cited concerns that promotion from among its graduates might lead to decreased scientific output and productivity, reduced outside circulation of knowledge, limited hiring scope, perpetuation of the existing academic culture, and decreased diversity in collaboration patterns. ${ }^{15-17}$ Although these concerns exist, promotion from within might also provide benefits such as enhanced stability and institutional memory, and long-term retention.

Among the degrees obtained from deans and chairs included in this study, a total of 76 degrees were conferred by institutions outside the US, with India and Canada being the most common. The incorporation of deans and chairs with international backgrounds might be beneficial in providing an enhanced ability to address health care disparities, a diverse leadership administration to model cultural differences, and an increase in creativity and innovation. ${ }^{18,19}$ The Institute of Medicine 


\section{American Journal of Pharmaceutical Education 2017; 81 (7) Article 5928.}

has noted that diversity among health care professionals is associated with decreased health disparities and improved health care outcomes for minority patients. ${ }^{20}$ Thus, diversity within pharmacy leadership might promote and encourage diversity among students to ultimately create more diverse health care practitioners. ${ }^{21}$

Nine of the 10 institutions with the greatest number of degrees conferred among deans and chairs recently ranked within the U.S. News and World Report's top 25 colleges and schools of pharmacy. ${ }^{22}$ Three institutions (Texas, Purdue, Minnesota) ranked among the top 25 for graduate programs in chemistry and one institution (California at San Francisco) ranked among the top 25 for graduate programs in the biological sciences and among the top 25 for best global universities. ${ }^{23-25}$ Perceived institutional reputation could offer candidates for leadership positions a competitive networking advantage. The actual correlation of degree conferring institutional reputation to the educational background of leaders in pharmacy academia, however, remains unexplored. Whether these particular institutions also provide better leadership development opportunities for graduates of their professional and/or graduate degree programs also is unknown. Finally, interpretation of the significance of these results is also limited by the significant recent growth in the overall number of colleges and schools over the last 20 years. The contributions of more newly established colleges and schools to future leadership in pharmacy academia remains to be determined. Nevertheless, our results provide a baseline for parallel future comparisons of the contributions of institutions to the educational background of deans and chairs.

The average tenure in the current deanship is approximately five years, which is comparable with previous studies that had reported an average tenure of six years. ${ }^{8}$ The tenure of current chairs is also approximately five years, but this figure has increased slightly compared to previous data for which almost half had been serving in a chair position for three years or less, ${ }^{7}$ and these data suggest similar turnover rates as observed in previous studies. This could indicate that even with the recent expansive growth in new schools, factors that might influence retention, such as job satisfaction, workload and stress, and mentorship ${ }^{26}$ have remained consistent.

The primary source of data for the study was derived from the public domain, including official school websites, professional websites such as LinkedIn, and search engines such as Google. Approximately onefifth of deans and chairs had curricula vitae available through their university website. This method of data collection is subject to error due to reporting, because information that was available on the internet might not have been current or might have been erroneous. As a result, the dynamic changes occurring in turnover rates and the attainment of degrees, trainings, and credentials might not have been captured accurately. However, because this cross-sectional study had a very narrow data collection window (three months), the findings are not expected to have been significantly affected. Additionally, one study found that gathering self-reported data from public LinkedIn profiles versus data that are privately self-reported (eg, private profiles and traditional resumes) might actually promote increased honesty, providing more accurate data for verifiable information like educational background and prior work experience. ${ }^{27}$ In addition, this study offers only a snapshot of deans and chairs at their current institutions and does not capture their previous external experiences. From our data, it is unknown whether the deans or chairs were previously employed by their alma maters prior to their current appointments. Finally, caution should be taken in interpreting the results, because the purpose of the study was to characterize the current educational background and training of deans and chairs, and not to define the attributes that constitute a qualified dean or chair.

\section{CONCLUSION}

The results of our study provide a contemporary snapshot of the educational attainment of chairs and deans. The majority of chairs and deans held a pharmacy professional degree, consistent with previously observed trends in educational attainment of these leaders. Our results also provide new insight into post-graduate training trends and participation in academy-sponsored leadership training opportunities among chairs and deans. Taken together, the prevalence of pharmacyrelated degrees and experiential diversity in the form of post-graduate educational and leadership training appears to be increasing among chairs and deans within US pharmacy schools. While promotion from within appears to be less common among chairs and deans than faculty, the actual significance of its impact remains to be determined. As pharmacy schools continue to expand, future research should employ a mixed methods approach to continue investigating the educational attainment, employment experience, and personal characteristics (ie, interest in and motivation for pursuing a leadership position) of deans and chairs, institutional hiring trends (promotion from within vs seeking external candidates), and how these characteristics compare between new and established programs over time. 


\section{American Journal of Pharmaceutical Education 2017; 81 (7) Article 5928.}

\section{REFERENCES}

1. Accreditation Council for Pharmacy Education. Accreditation statistics. https://www.acpe-accredit.org/students/faqs.asp\#5. Accessed June 27, 2016.

2. Assemi M, Hudmon KS, Sowinski KM, Corelli RL. Educational background and academic rank of faculty members within US schools of pharmacy. Am J Pharm Educ. 2016;80(4):Article 61. 3. American Pharmacists Association, American Society of HealthSystems Pharmacist. Concerns about the accelerating expansion of pharmacy education: time for reconsideration. http://www.ashp.org/ DocLibrary/News/Accelerating-Expansion-of-Pharmacy-Education. aspx. Accessed November 9, 2016.

4. Knapp DA, Knapp DE. Attributes of colleges and schools of pharmacy in the United States. Am J Pharm Educ. 2009;73(5):Article 96.

5. Maine LL, Vlasses PH. Assessing quality in pharmacy education in an era of rapid expansion. J Am Pharm Assoc. 2012;52(4):528-534. 6. Accreditation Council for Pharmacy Education. Accreditation standards and key elements for the professional program in pharmacy leading to the doctor of pharmacy degree. Standards 2016. https:// www.acpe-accredit.org/pdf/Standards2016FINAL.pdf. Accessed November 9, 2016.

7. Schwinghammer TL, Rodriguez TE, Weinstein G, et al. AACP strategy for addressing the professional development needs of department chairs. Am J Pharm Educ. 2012;76(6):Article S7. 8. Draugalis JR, Plaza CM. A 20-year perspective on preparation strategies and career planning of pharmacy deans. Am J Pharm Educ. 2010;74(9):Article 162.

9. Thompson DF, Callen EC. Publication records among college of pharmacy deans. Ann Pharmacother. 2008;42(1):142-143.

10. Thompson DF, Callen EC, Nahata MC. Publication metrics and record of pharmacy practice chairs. Ann Pharmacother. 2009;43:268275.

11. American Association of Colleges of Pharmacy. Alumni AACP fellows. http://www.aacp.org/career/leadership/Pages/Cohortlists. aspx. Accessed November 9, 2016.

12. Svensson CK. Should a pharmacy dean be a pharmacist? Am J Pharm Educ. 2015;79(3):Article 32.

13. Bell HS. Should a pharmacy dean be a pharmacist? Am J Pharm Educ. 2015;79(3):Article 33.

14. Chisholm-Burns MA. Diversifying the team. Am J Pharm Educ. 2008;72(2):Article 44.

15. Eells WC, Cleveland AC. Faculty inbreeding. J Higher Educ. 1999;70(5):579-588.
16. Altbach PG, Yudkevich M, Rumbley LE. Academic inbreeding: local challenge, global problem. Asia Pac Educ Rev. 2015;16(3):317330 .

17. Horta H. Deepening our understanding of academic inbreeding effects on research information exchange and scientific output: new insights for academic based research. Higher Educ. 2013;65(4):487-510. 18. Nkansah NT, Youmans SL, Agness CF, Assemi M. Fostering and managing diversity in schools of pharmacy. Am J Pharm Educ. 2009;73(8):Article 152.

19. White C, Louis B, Persky A, et al. Institutional strategies to achieve diversity and inclusion in pharmacy education. Am J Pharm Educ. 2013;77(5):Article 97.

20. Smedley BD, Butler AS, Bristow LR (eds). In the Nation's Compelling Interest. Ensuring Diversity in the Health-care Workforce. Washington, DC: National Academies Press; 2004:1-22. 21. O'Connell MB, Jackson AN, Karaoui LR, et al. Cultural competency in health care and its implications for pharmacy Part 3B: emphasis on pharmacy education policy, procedures, and climate. Pharmacotherapy. 2013;33(12):e368-e381.

22. U.S. News and World Report. Best Pharmacy Programs. Ranked in 2016. http://grad-schools.usnews.rankingsandreviews.com/bestgraduate-schools/top-health-schools/pharmacy-rankings. Accessed November 9, 2016.

23. U.S. News and World Report. Best Grad Schools. Graduate schools, chemistry programs. http://grad-schools.usnews. rankingsandreviews.com/best-graduate-schools/search? program $=$ top-chemistryschools\&name $=\&$ sort $=$ program_rank $\&$ sortdir $=$ asc. Accessed November 9, 2016.

24. U.S. News and World Report. Best Grad Schools. Graduate schools, Biological Sciences Programs. http://grad-schools.usnews. rankingsandreviews.com/best-graduate-schools/search? program $=$ top-biological-sciences-

programs\&sort $=$ program_rank\&sortdir $=$ asc. Accessed November 9, 2016.

25. U.S. News and World Report. Best Global Universities Rankings. Ranked in 2016 for 2017. http://www.usnews.com/ education/best-global-universities/rankings. Accessed November 9, 2016.

26. Carter O, Nathisuwan S, Stoddard GJ, Munger MA. Faculty turnover within academic pharmacy departments. Ann Pharmacother. 2003;37(2):197-201.

27. Guillory J, Hancock JT. The effect of LinkedIn on deception in resumes. Cyberpsychol Behav Soc Netw. 2012;15(3):135-140. 